\title{
Interaction of light and gravity signals as a mechanism of counteracting alterations caused by simulated microgravity in proliferating plant cells
}

\section{Aránzazu Manzano}

Consejo Superior de Investigaciones Cientificas

\section{Veronica Pereda-Loth}

Universite Toulouse III Paul Sabatier - Complexe Scientifique de Rangueil

\section{Anne de Bures}

Universite de Perpignan

Julio Sáez-Vásquez

Universite de Perpignan

\section{Raúl Herranz}

Consejo Superior de Investigaciones Cientificas

\section{F. Javier Medina ( $\square$ fjmedina@cib.csic.es)}

Consejo Superior de Investigaciones Cientificas https://orcid.org/0000-0002-0866-7710

\section{Research article}

Keywords: Gravitropism, Phototropism, Abiotic Stress, Root Meristem, Cell Cycle, Ribosome Biogenesis, Nucleolin, Space Plant Biology

Posted Date: May 29th, 2020

DOl: https://doi.org/10.21203/rs.3.rs-29236/v1

License: (c) (1) This work is licensed under a Creative Commons Attribution 4.0 International License. Read Full License 


\section{Abstract \\ Background}

Light and gravity are fundamental cues for plant development on Earth. In space, understanding the effects of changing conditions affecting to these two stimuli is key for optimizing the life support systems to come with space exploration. Simulated microgravity is useful as a complement to real spaceflight experiments into refining our knowledge of early plant development adaptation to extraterrestrial environments.

\section{Results}

In wild type Arabidopsis and in mutants of the two genes of the essential nucleolar protein nucleolin (nuc1 and nuc2), the use of an extended toolbox of cell proliferation, cell growth and ribosome biogenesis markers, has allowed us to show that the incorporation of an illumination regime, in this case photoperiod, has been sufficient to attenuate or suppress the effects caused by gravitational stress at the cellular level in the root meristem. These results are consistent with other experiments carried out at real and simulated microgravity in which early plant development is nominal when the environmental conditions are optimal (nutrients, light, temperature, humidity).

\section{Conclusions}

Light signals may total or partially replace gravity signals significantly improving plant growth and development in microgravity. Despite that, molecular alterations are still compatible with the expected adaptation mechanisms that should be better understood. The differential sensitivity of nuc 1 and nuc2 mutants to gravitational stress points to new strategies to produce more resilient plants to travel with humans in new extraterrestrial endeavors.

\section{Background}

Plants live in dynamic environments, with frequent changes in many parameters, such as temperature, humidity, water and light. Since plants are sessile organisms, they have developed different directional responses to modulate their growth according to them, which are termed tropisms. The two major tropistic cues are gravity and light [1]. Gravitropism and phototropism drive plant growth and development by producing opposite effects in the roots and in the aerial parts of the plant. Roots grow in the opposite direction to the light source and in the direction of the gravity vector (negative phototropism and positive gravitropism), whereas the aerial parts show negative gravitropism and positive phototropism [2]. The phytohormone auxin is a key factor in the transduction pathway of the tropistic response to these two signals, playing a mediating role between perception and response $[3,4]$. 
Plant development, driven by tropistic cues, is supported by the activity of the meristematic tissues. These tissues are characterized by the balance between cells actively proliferating, involved in a continuous cell cycle, and the cells escaping from the cell cycle to differentiate $[5,6]$. In fact, meristems constitute the source of cells for growth and differentiation, being the cellular basis for the developmental program of the plant. Meristematic cells are undifferentiated highly proliferating cells, which maintain a strict coordination between cell proliferation and cell growth, which is termed "meristematic competence" [7].

The growth of meristematic cells is not merely an increase in size, but it depends on a continuous supply of proteins, enabling them to reach the critical size necessary for cell division. Ribosomes are the protein factories of cells, so the rate of ribosome biogenesis is directly correlated to the cell growth [8, 9]. This means that, in proliferating meristematic cells, cell growth is ultimately determined by the RNA polymerase I activity, which controls ribosomal RNA synthesis and ribosome biogenesis in the nucleolus [10]. An unequivocal functional link between the rate of ribosome biogenesis and the nucleolar ultrastructure has been demonstrated in plants, using cellular models characterized by a high activity of cell proliferation $[11,12]$. Ribosome biogenesis is indeed a complex process integrated by multiple steps. The nucleolar protein nucleolin is the most abundant protein of exponentially growing cells and plays a major role in the regulation of ribosome biogenesis at different levels, namely rDNA chromatin structure, rRNA gene transcription, pre-rRNA processing and export of pre-ribosomal particles, and even in the structural organization of the nucleolus [13-15]. The Arabidopsis thaliana genome contains two nucleolin genes, termed NUC1 and NUC2. Under normal conditions, NUC1 is expressed at a high rate, mostly in proliferating tissues [16], whereas the protein NUC2 plays a role in rDNA chromatin dynamics, preferentially at developmental transitions [17]. Furthermore, NUC2 is involved in the plant stress response [18].

Meristems are a primary target of tropistic cues. In the case of light, specialized photoreceptor proteins phytochromes - are modulators of cell proliferation and cell growth in meristems. This modulation is different for the shoot and for the root meristematic cells, in agreement with the opposite phototropic behavior of the shoot and the root. In the shoot apical meristem, light irradiation plays an activating role, promoting the cell cycle progression of cells previously arrested at G1 or G2 phases in darkness [19, 20]. In contrast, in the root meristem, light induces the production of flavonols and other metabolites resulting in a reduction of the cell proliferation rate [21]. Light also regulates indirectly cell proliferation and cell growth via photosynthesis. Sugars synthesized in the photosynthetic process play a regulatory role in meristematic tissues. Glucose binds to the central regulator TOR kinase inducing the activation of cell proliferation, through the expression of S-phase genes, and ribosome biogenesis [9, 22, 23].

The other major tropistic cue, gravity, has also an impact on meristematic activity. Gravity alterations induce changes of the rate of cell proliferation and cell growth in root meristematic cells, as it was shown in experiments under real or simulated microgravity. These experiments were performed in darkness conditions (i.e. without any major tropistic cue) and using a culture medium supplemented with sucrose $(10 \mathrm{~g} / \mathrm{I})$. In these cells, the lack of gravity appeared as a stress condition, resulting in the disruption of the 
meristematic competence. Arabidopsis thaliana seedlings grown under microgravity and darkness showed an increase in the cell proliferation and a depletion of cell growth $[24,25]$. These alterations were accompanied by an inhibition of auxin polar transport in root tips [26]. The absence of gravity is a major environmental change existing during spaceflight, and planets and satellites other than the Earth are characterized by a different level of gravity compared to our planet. Therefore, alterations on the growth and development of plants caused by changes in gravity may compromise the culture of plants for human space exploration, or future human settlement in other planets. Higher plants are indeed an essential component of the Life Support Systems that must be implemented for these purposes.

In view of the fundamental role played by phototropism and gravitropism on meristematic activity, we have attempted to better understanding the interactions between the two main tropistic signals with the specific purpose of discriminating whether or not light could act as a countermeasure to reverse the effects caused by the lack of gravity orientation in darkness, and in what extent. We have conducted experiments using the Random Positioning Machine (RPM), a reliable and well-characterized microgravity simulator [27]. We have applied two illumination regimes, either photoperiod or darkness, and we have evaluated the status of meristematic competence (the balance between cell proliferation and cell growth) in the root, in 6-day-old seedlings, that is, during the early stages of plant development. We have paid special attention to the process of ribosome biogenesis, whose importance is fundamental for maintenance of meristematic competence. [12]. Some analyses have been performed separately in roots and hypocotyls (aerial parts) of seedlings grown in different conditions. The results of these experiments have shown that light can effectively replace gravity, at least partially, as tropistic cue driving plant development, by attenuating the effects caused by microgravity on the root meristem.

\section{Results}

\section{Seedling growth: root and hypocotyl orientation and length}

Seedlings of Col-0, nuc 1 and nuc 2 genotypes were grown for 6 days in vertical position ( $1 \mathrm{~g}$ control), either with photoperiod regime or darkness conditions. A reduction of the seed germination rate and some growth retardation was appreciated for nuc1 mutants, which showed an irregular growth rate. In all cases, seedlings showed their roots oriented in the direction of the gravity vector and opposite to light source (positive gravitropism and negative phototropism). Hypocotyls were oriented opposite to gravity and, in the case of illumination, towards the top light source, (negative gravitropism and positive phototropism) (Fig. 1, A-F). Simulated microgravity samples with photoperiod regime presented the same orientation as $1 \mathrm{~g}$ control samples, except for a slight disorganization of the roots, while samples grown in darkness and microgravity (without any tropistic cues) showed a total disorganization in their growth (random growth) (Fig. 1, G-L). However, a conspicuous skewness was observed to affect hypocotyls, in the conditions of absence of light and gravity. This effect was especially relevant for the wild type (Col-0) seedlings, in which hypocotyls showed a sort of parallel alignment, and it appeared relatively attenuated in the two mutant lines (Fig. 1). It is noteworthy that this skewness of hypocotyls was restricted to the conditions of microgravity and darkness and it did not appear in any other condition. 
Root length was shorter in all seedlings grown in darkness (except in the case of the nuc1 mutant) (Fig. 2A, C) and this parameter showed a general slight decrease in all samples grown in microgravity and photoperiod, being only this decrease significant respect to corresponding $1 \mathrm{~g}$ control in the nuc2 mutant (Fig. 2A). In contrast, this parameter was not affected, in comparison with control condition, in any of the strains grown in microgravity and darkness (Fig. 2C).

Hypocotyls appeared clearly elongated in seedlings grown in darkness (etiolated seedlings) in all strains and gravity conditions (Fig. 2). For seedlings grown under photoperiod, the change in the gravity level did not produce any effect on the hypocotyl length (Fig. 2B). However, in darkness, some differences appeared in the three strains, and the nuc2 mutant presented a significant hypocotyl length decrease when this line was grown in simulated microgravity conditions (Fig. 2D).

\section{Pre-rRNA processing study}

\section{Pre-rRNA processing in the aerial part (hypocotyl)}

Alterations in the ribosome biogenesis process in hypocotyls were investigated by analyzing different steps of $45 \mathrm{~S}$ pre-rRNA (primary transcript) processing by RT-PCR. We detect nucleotide sequences corresponding to different regions of the transcript whose cleavage occurs at known steps of the transcript processing. These sequences corresponded to 5'ETS and 3'ETS only, or 5'ETS/18S and 25S/3 'ETS transcripts (Pontvianne et al. 2010) (Fig. 3A). The analysis by RT-PCR searched potential enrichments in intermediate RNAs, which could account for changes in the accumulation of $45 \mathrm{~S}$ pre-rRNA and/or processed spacer sequences.

When comparing the amplified bands, as observed in an agarose electrophoresis, linked to the different steps of $45 S$ pre-rRNA processing, no differential patterns were observed in simulated microgravity under any light regime (photoperiod or darkness) for any Arabidopsis thaliana line, when they were compared to the control condition ( $1 \mathrm{~g}$ ) (Fig. 3B, C). Quantification of the ratios between band intensity, performed using Image J software, and of the 25S/18S rRNA ratio, did not reveal differences between conditions (Suppl. S2 and S3; Suppl. S4 and S5).

\section{Pre-rRNA processing in the root}

Root biomass in Arabidopsis seedlings is lower than hypocotyl biomass. Therefore, the amount of RNA that we could extract from the root is a constraint for the methods of analysis potentially usable. Due to this constraint, a slightly different approach was used to detect alterations in ribosome biogenesis in the root.

The efficiency of primary transcript processing (45S pre-rRNA) in roots was analyzed by RNA quantification at both ends of the transcript (5'ETS and 3'ETS) and by quantification of 25S rRNA by RTqPCR (Fig. 4A). Quantification of terminal RNA sequences of the primary transcript could serve to detect alterations in early pre-rRNA processing, whereas different levels of 25S rRNA would indicate a general alteration of ribosome biosynthesis [28, 29]. 
When the seedlings grew in the RPM $(\operatorname{Sim} \mu g)$ with photoperiod regime, the 25S rRNA showed a greater accumulation for all strains (Col-0, nuc1 and nuc2). However, sequences at both ends of the primary transcript (5'ETS and 3'ETS) only appeared accumulated in Col-0 and nuc2 mutant, but they appeared reduced in nuc1 mutant. Comparisons were always done with respect to $1 \mathrm{~g}$ control (Fig. 4B).

On the other hand, in seedlings subjected to microgravity without light the ETS pre-rRNA accumulation was different for the two ends. For 5'ETS, it was higher in wild type (Col-0), but lower in nuc1 mutant, whereas the 3'ETS extreme showed a lower level in the two mutant lines (nuc1 and nuc2), when compared to levels obtained for their corresponding $1 \mathrm{~g}$ controls. The $25 \mathrm{~S}$ rRNA accumulation was statistically greater in nuc2 mutant and lower in nuc1 mutant, in comparison with $1 \mathrm{~g}$ control condition. (Fig. 4C).

\section{Factors of meristematic competence: microscopical analyses in the root tip}

\section{Cell proliferation: number of cells/mm}

The rate of local cell production (LCPR, number of cells $/ \mathrm{mm}$ in cell rows) is a parameter indicative of cell proliferation activity [6]. This parameter was measured in root meristematic cell layers, identified in a central optical section from the z-stack obtained with a confocal laser microscope, after root staining with the "Renaissance" dye for selective visualization of the cell wall [30].

Simulated microgravity (RPM), along with photoperiod regime, had no effect on this parameter, since no statistically significant differences between microgravity samples and $1 \mathrm{~g}$ control samples were observed (Fig. 5A). In contrast, in darkness, samples grown under simulated microgravity showed a clear trend of this parameter to decrease with respect to the control, being statistically significant only in nuc1 mutant (Fig. 5B).

\section{Cyclin B1 expression}

Cyclin B1 gene expression is an indicator of the cell proliferation activity, due to its regulator role in the G2/M cell cycle transition checkpoint [31]. The use of the CYCB1: uidA reporter line allowed the estimation of the expression of this gene by GUS staining, whose intensity was quantified in root meristems by measuring the Integrated Optical Density (IOD) parameter.

In samples grown under photoperiod, the expression of this gene was apparently not affected by the level of gravity, since no quantitatively significant differences could be appreciated between samples grown in simulated microgravity and those grown in $1 \mathrm{~g}$ ground gravity level control (Fig. 5C). In general, we noticed that the GUS staining corresponding to the expression of the cyclin B1 gene was rather weak in all cases. 
However, the GUS staining was especially weak in seedlings grown for 6 days in darkness, whatever the level of gravity, most probably due to the low availability of sugars in conditions preventing photosynthesis to be performed. In these samples, quantification of staining resulted in 10-times lower levels than those found in samples grown under a photoperiod regime, and differences in staining intensity depending on the gravity level could not be appreciated (not shown).

\section{Cell growth: nucleolar area}

The nucleolar size is a parameter closely correlated with the rate of ribosome biogenesis and hence with cell growth in actively proliferating meristematic cells [8,32]. Nucleolar size was estimated with the confocal microscope by quantification of the area immunostained by anti-fibrillarin antibody in the root meristematic cell layers from a central optical section.

Nucleolar size was statistically unaltered in the comparison of seedlings grown in simulated microgravity (RPM) and ground control ( $1 \mathrm{~g}$ ) when they were grown under a photoperiod regime (Fig. 6A). On the contrary, the experimental condition of simulated microgravity and darkness produced a clear effect on nucleolar size/cell growth. In this condition, a general trend was detected under simulated microgravity, consisting of a decrease of this parameter in all Arabidopsis thaliana lines. This decrease reached statistical significance in both nuc1 and nuc2 mutants (Fig. 6B).

\section{Auxin distribution pattern}

The DII-VENUS transgenic reporter line was used for analyzing the auxin distribution pattern in the distal part of the root under simulated microgravity for the two light conditions, by comparing the pattern shown in this condition with that observed in the $1 \mathrm{~g}$ control condition.

The reporter gene of the DII-VENUS line is a YFP construction in phase with the DII domain of the Aux/IAA protein and a nucleus location sequence. The degradation of the fusion protein is catalyzed by the $\mathrm{SCF}^{\mathrm{TIR} / \mathrm{AFB} 1-5}$ ubiquitination complex in presence of auxin. Consequently, the fluorescence signal intensity observed in the cell nucleus when using this transgenic line is inversely proportional to the presence of this phytohormone [33].

The fluorescence pattern obtained in seedlings subjected to simulated microgravity with photoperiod regime was essentially similar to the control pattern of seedlings grown at $1 \mathrm{~g}$, in which no lateral imbalance or alteration of auxin distribution in the root was observed (Fig. 7, top). On the contrary, the fluorescence pattern obtained in samples grown in simulated microgravity and darkness showed a lower signal intensity in the meristematic cell layers, central cylinder and columella cells, compared with $1 \mathrm{~g}$ control, indicating that the lack of gravity stimulus alters the auxin distribution in the root. More auxin is accumulated in the distal part of the root, indicating that the transport of this phytohormone is altered, or even inhibited (Fig. 7, bottom). In general, the intensity of labeling was higher in the samples grown with photoperiod than in samples grown in darkness (Fig. 7). This means that, whatever the gravity conditions, 

in simulated microgravity.

\section{Factors of meristematic competence: molecular biology analysis}

In addition to the cellular analysis of the factors of meristematic competence, we have performed a complementary approach to the same biological functions (cell proliferation, cell growth and auxin polar transport) by means of a transcriptomic (RT-qPCR) study with RNA extracted from roots.

The analysis investigated, in the conditions of gravity and light used throughout this paper, the expression changes of three sets of genes, selected as markers of these functions. The first set was composed of two genes involved in auxin polar transport (EIR/PIN2), and auxin perception (TIR); the second set was composed of genes indicators of cell proliferation status, since they are involved in cell cycle regulation ( $C Y C B 1 ; 2$ and $C K 2 A ; 2)$; finally, the third set was composed of genes involved in the regulation of ribosome biogenesis (NUC1, NUC2 and FIB), hence indicators of cell growth status.

The analysis of the relative expression of these genes (Fold Change) in seedlings of the three lines grown under simulated microgravity (RPM) and photoperiod regime, compared with the $1 \mathrm{~g}$ control condition, showed that the gravity alteration produces a general downregulation, differently affecting the concerned functions and the different lines. The auxin polar transport was altered, as indicated by the decrease of EIR gene expression in all strains. Also, in nuc1 mutant, a pronounced decrease in the expression of the auxin receptor TIR was produced (Fig. 8A). The expression of $C Y C B 1 ; 2$ gene also experienced a marked decrease in simulated microgravity conditions in the wild type line (Col-0) and in both mutant lines (nuc1 and nuc2). In contrast, CK2A;2 expression was only detected as significantly decreased in nuc1 mutant (Fig. 8A). In turn, the expression of the cell growth markers showed less clear changes. Only a decrease of NUC2 gene for nuc1 mutant and an increase of FIB gene for nuc2 mutant reached statistical significance, while no alteration of any of these markers was produced in Col-0 line (Fig. 8A).

The results in darkness conditions showed, in general, the opposite trend. The auxin transport markers were altered in simulated microgravity and darkness, as shown by the general (Col-0, nuc1 and nuc2) increase in TIR gene expression. An increase in expression of EIR gene was produced only in nuc2 mutant (Fig. 8B). In the case of cell proliferation markers, the $C Y C B 1,2$ gene showed a decrease of its expression in nuc1 mutant, but an increase in nuc2 mutant, whereas the expression of $C K 2 A ; 2$ gene appeared only incremented in Col-0 plants (Fig. 8B). The expression of all cell growth markers (NUC1, NUC2 and FIB) was upregulated when compared to $1 \mathrm{~g}$ control in wild type (Col-0) seedlings, whereas in nucleolin mutant lines (nuc1 and nuc2) upregulation only appeared as a trend, only reaching statistical significance in FIB gene expression in the nuc2 (Fig. 8B).

\section{Discussion}


The Arabidopsis thaliana seedlings of three different genetic backgrounds (Col-0, nuc1 and nuc2) grown under simulated microgravity ( $\operatorname{Sim} \mu g$, RPM) with a photoperiod regime showed oriented hypocotyls and roots, the same as in $1 \mathrm{~g}$ control samples. In other words, since hypocotyls presented positive phototropism and the roots negative phototropism, and the phototropic axis coincided with the gravitropic axis, phototropism by itself was capable of driving the seedling growth in the absence of a gravitropic signal. However, plants in the absence of any tropistic signal to guide their growth, subjected to simulated microgravity and darkness, showed disoriented hypocotyls and roots, confirming the validation of the simulation system.

Several experiments carried out on board the International Space Station (ISS), in real microgravity, have shown that, without the gravitational cue, the position of the light source influences the growth direction of both the hypocotyl and the root. The Arabidopsis thaliana plants grown during APEX01 experiment in ABRS (Advanced Biological Research System) hardware with directional light (as in our experiment) showed hypocotyls and roots with an oriented growth, the same as the corresponding Earth control. In contrast, plants grown in microgravity in the CARA hardware with environmental light, or in darkness, showed hypocotyls and roots with a random growth direction [34, 35].

In addition, different studies performed in space experiments revealed non-random growth directions of seedling organs, when they developed in microgravity. In an experiment performed in the Space Shuttle STS-95 mission, most of rice roots elongated in a constant direction forming a constant angle of about $55^{\circ}$ relative to the axis of the caryopsis in the early phase of growth, but later the roots grew in various directions, including away from the agar medium [36]. In the GRAVI-1 experiment carried out in the ISS, lentil roots initially curved strongly away from the cotyledons and then slowly straightened out forming a relatively constant angle. This establishment of growth direction in a stimulus-free environment was termed automorphogenesis [37]. Furthermore, etiolated Arabidopsis seedlings grown in the space shuttle were shown to exhibit a left-handed skewing response [38]. Actually, the deviation of the root growth from the gravity direction, termed root skewing, was repeatedly described [39-41]. It has been demonstrated that it is independent of both the tropic force of gravity and the gravity-induced contact forces between roots and growth media, and, interestingly, it is more intense in the WS ecotype of Arabidopsis thaliana, than in the Col-0 ecotype. However, the molecular mechanisms underlying such growth phenomenon remain unresolved. Various genes and factors have been proposed to regulate skewing. These include a complex network of processes including polar auxin transport and cytoskeletal dynamics [40, 42]. A recent study in the ISS, using two mutants of skewing behavior, affecting different cellular functions, concludes that genes related to skewing could play a prominent role in plant spaceflight adaptation [43].

Interestingly, our results in simulated microgravity and different conditions of light have not revealed any special orientation of roots, but an evident skewing of hypocotyls was revealed in the absence of tropistic cues (darkness and simulated microgravity). This behavior of hypocotyls has not been previously described. In general, hypocotyl skewing has been paid little attention in studies of seedling growth in altered gravity. 
The existence of significant differences between the response of the root and the hypocotyl to different conditions of gravity and light is a novel finding of this work. Certainly, it is known a predominant effect of light on tropistic responses in the shoot [1]. Apparently, the presence of a directional light source is sufficient for the shoot to orient its growth towards this source and to develop correctly in microgravity, the same as it does in ground gravity level. Experiments conducted in shoot apical meristem of the Arabidopsis thaliana seedlings have demonstrated that white light is able to rescue the cell cycle arrest in G1/S and G2/M transitions caused by darkness, as well as to promote ribosome biogenesis efficiency $[19,20]$.

In particular, our study of the ribosome biogenesis using markers of different steps of 45S pre-rRNA transcript processing revealed a different sensitivity of this process to gravity and light in the hypocotyl and in the root. In the aerial part, neither simulated microgravity nor darkness appeared to alter this process in any of the genotypes analyzed (Col-0, nuc1 and nuc2) with respect to the control experiment, in $1 \mathrm{~g}$ and photoperiod. However, in root cells, processing of the primary pre-ribosomal transcript was affected under simulated microgravity with photoperiod regime in the wild type and nuc2 mutant, as indicated by the higher accumulation of 5'ETS and 3'ETS ends and 25S rRNA. This suggests an effect on the rate of production of ribosomes. Alterations of ribosome biogenesis induced by both real and simulated microgravity in root meristematic cells and in vitro cell cultures have been reported in previous experiments from our laboratory [25, 44-46]. Different indirect markers of the process have been used in these studies, such as the protein levels and gene expression regulation of nucleolin and fibrillarin, nucleolar proteins known to play a key regulatory role. Furthermore, the size and structure of the nucleolus have been used as faithful markers of the ribosomal biosynthetic activity. Indeed, three structural types of the nucleolus were defined as corresponding to different rates of ribosome biogenesis rate, namely vacuolated (highly active and present mainly in $\mathrm{G} 2$ phase of the cell cycle), compact (active and characteristic of the G1 phase) and fibrillar (inactive and present in the GO phase). Under simulated microgravity conditions, the percentage of vacuolated and compact nucleoli decreased significantly, consistently with a lower efficiency of ribosome biogenesis $[44,45]$. The results of the present work confirm these alterations and identify specific steps of the mechanism that appear modified due to the environmental change.

The results obtained in the nuc1 mutant are of particular interest. In a previous paper, the effects of simulated microgravity on this mutant line were described by looking at the ultrastructure of the nucleolus, which was shown severely damaged, containing the so-called "nucleolar peri-chromatin-like granules", which are the structural expression of a bad processing of pre-rRNA [46]. This effect actually represents an intensification, caused by simulated microgravity, of the defective pre-rRNA processing that occurs naturally in this mutant under control $1 \mathrm{~g}$ gravity conditions [16]. In the present experiment, the higher accumulation of $25 \mathrm{~S}$ rRNA indicates an unbalanced processing of $45 \mathrm{~S}$ primary transcript prerRNA, and the lower accumulation of the intermediate 5'ETS and 3'ETS pre-rRNA ends expresses an acceleration of the processing mechanism. Interestingly, despite these severe alterations, the nuc1 mutant is viable, not only when grown under control $1 \mathrm{~g}$ gravity conditions, but also when subjected to simulated microgravity. 
The status of meristematic competence has been assayed in roots of seedlings (Col-0, nuc1 and nuc2) grown under simulated microgravity and light (photoperiod) by means of the estimation of cellular parameters (cells/mm ratio in meristematic cell layers, cyclin B1 expression in situ and nucleolar area immuno-labelled by fibrillarin). Our results indicate that seedlings maintain the coordination of growth and proliferation in meristematic cells at equivalent levels to the $1 \mathrm{~g}$ control. This means that the microgravity stress can be compensated at the cellular level by means of light. In other words, phototropism can counteract the lack of gravitropism, at least to a certain extent. These results are in agreement with a previous experiment carried out in a clinostat [46]. In general, there is increasing evidence that light is an important regulator of stress acclimation processes [47].

However, when comparing the general response to microgravity at the molecular level (Fig. 8), nuc1 shows a differential pattern of expression of marker genes, not only for the genes affecting ribosome biogenesis, but also for genes related to auxin transport and cell cycle regulation. It appears that the alterations inherent to this mutant, that reduce its efficiency in the production of ribosomes with respect to the wild type, also alter its response to gravitational stress in other physiological processes somehow related to ribosome biogenesis and meristematic competence. Therefore, the nuc1 mutant would have a reduced ability to counteract the lack of gravity, while the wild type and nuc2 mutant share a common profile (but gene fold ratios are smaller in the case of nuc2). It should be noticed that NUC2 protein is a stress-related variant of nucleolin [18]. Therefore, the similar, but attenuated response to gravitational stress in this mutant could be interpreted as a sign of resilience to an adverse environmental condition.

In particular, we have found expression changes in marker genes of cell proliferation and auxin transport in the root meristem. Whereas a decrease in the EIR(PIN2) gene expression was recorded in the three plant genotypes (Col-0, nuc1 and nuc2), this expression change was not accompanied by any alteration of the auxin distribution pattern observed in the DII-VENUS line between the samples grown in microgravity and the $1 \mathrm{~g}$ control. In two space experiments, namely CARA (with environmental light from Destiny module of ISS) and APEX03-2 (with directional light supplied by the Vegetable Production System hardware), no differences in the root meristem fluorescence pattern of pDR5r::GFP line were observed (Ferl y Paul 2016). Therefore, the expression changes in a particular auxin transport gene (EIR) suggest that the process is sensitive to microgravity, but, in the presence of light, the overall efficiency of the process would not be significantly altered. The functional redundancy between PIN proteins [48-50] could be capable of counteracting the observed alterations of gene expression.

The most severe alteration observed concerned the expression levels of the $C Y C B 1 ; 2$ gene, which showed an important decrease in simulated microgravity with respect to ground control $(1 \mathrm{~g})$ for WT, nucl and nuc2 plants, even under photoperiod. Previous observations reported by our laboratory in real microgravity and in ground-based facilities, have consistently shown a decrease of CYCB1 gene expression. This included histochemical measurements of GUS staining in Arabidopsis thaliana reporter lines (Manzano et al. 2009; Matía et al. 2009), as well as RT-qPCR experiments in a cell culture exposed for $3 \mathrm{~h}$ to simulated microgravity. In the latter case, the observed shortening of the $\mathrm{G} 2$ phase of cell cycle 
did not produce any change of cell size between the two experimental conditions [45]. As in the present case, a molecular alteration was not correlated with any change at the cellular level.

\section{Conclusions}

The incorporation of an illumination regime, in this case photoperiod, has been sufficient to attenuate or suppress the effects caused by gravitational stress, and that plants can grow and develop correctly (no alterations at the cellular level) in microgravity, showing only alterations at the molecular level. Therefore, and, as shown by other experiments carried out at real [51-53] and simulated microgravity [46,54], if the growth conditions are optimal (nutrients, light, temperature, humidity) the plants present a correct growth in their first stages of development. Despite that, molecular alterations are still compatible with the expected adaptation mechanisms involving the modulation of duplicated and specialized genes, expressed under environmental stress, such as NUC2, that should be promoted to increase the plant acclimation to a new extraterrestrial environment.

\section{Methods}

\section{Experimental setup and seedling growth conditions}

In these experiments, five lines of Arabidopsis thaliana, ecotype "Columbia" were used, namely the wild type strain (Col-0) (initially obtained from the commercial source "Lehle Seeds", Round Rock, TX, USA, and then propagated in our laboratory), two mutants of the nucleolin protein gene (nuc1.2 and nuc2.2) $[16,17]$ (Nottingham Arabidopsis Stock Centre nuc1.2: Salk_002764; nuc2.2: GABI178D01), a reporter line of cyclinB1 gene expression, CYCB1:uidA [55] (Nottingham Arabidopsis Stock Centre CS68143), and a reporter line of auxin distribution pattern, DII-VENUS [33] (Nottingham Arabidopsis Stock Centre CS799173). Since these materials and strains are publicly available, no deposit of any specimen in any public herbarium has been done.

Seeds were sterilized for 4 min in 70\% (v/v) ethanol (Sigma\#270741) and 1\% (v/v) Triton X-100 (Sigma\#T9284) and washed two times for 1 min each rise with 95\% ethanol. Once dried, seeds were glued on a nitrocellulose membrane (VWR\#28149-472) with Gum Guar (1\% w/v, Sigma\#G-4129). In the case of seedlings grown for transcriptomic analysis (to be frozen at $-80^{\circ} \mathrm{C}$ after growth), seeds were arranged in two rows (100 seeds/row). When seedlings were grown for microscopical analysis (to be chemically fixed after growth), seeds were arranged in a single row (30 seeds/row).

Membranes containing seeds were placed on $6 \mathrm{~cm}$ diameter Petri dishes containing $0.8 \%(\mathrm{w} / \mathrm{v})$ agar with $1 / 2$ MS (Murashige and Skoog's, Duchefa) plant culture medium, half strength, without sucrose, and they were stratified at $4^{\circ} \mathrm{C}$ for 2 days in order to produce a quick and synchronous germination.

Petri dishes were mounted in the Random Positioning Machine (desktop RPM, Université III-Paul Sabatier, Toulouse-France) (ground microgravity simulator, $\leq 10^{-4} \mathrm{~g}$ ) (Borst y Van Loon 2009) (Suppl. Fig. S1), 
where seeds germinated and seedlings grew at $22{ }^{\circ} \mathrm{C}$ with $80 \%$ relative humidity for 6 days. One half of the seedlings was grown in continuous darkness, and the other half was grown under a photoperiod light regime (16 h unidirectional white light/ $8 \mathrm{~h}$ darkness).

For each experiment, we performed a control at the Earth gravity level ( $1 \mathrm{~g}$ Control). In the control condition, the plants grew in Petri dishes attached to the frame of the RPM, under the same conditions of temperature, humidity, illumination, and even vibrations, as the RPM samples (distance from LEDs to seedlings was $40 \mathrm{~mm}$, photosynthetic photon flux (White X4 Ultra Brigth LED Lamps Reference AND420HWA) was $40 \mu \mathrm{mol} \mathrm{m}^{-2} \mathrm{~s}^{-1}$ ).

After the growth period, the plates with 200 seeds were directly frozen at $-80^{\circ} \mathrm{C}$, whereas the plates with 30 seeds were open to take images and the seedlings were quickly recovered from the dishes and transferred into the fixative solutions (maximum time until fixation was $15 \mathrm{~min}$ ). The Col-0, nuc1, nuc2 and DII-VENUS plants were immersed in $5 \%(\mathrm{v} / \mathrm{v})$ paraformaldehyde, while CYCB1:uidA plants were dehydrated in cold acetone $\left(-20^{\circ} \mathrm{C}\right)$.

\section{Sample processing for microscopy analyses}

\section{Immunofluorescence and nucleolar area quantification}

Seedlings were fixed in 5\% (v/v) paraformaldehyde in PBS, $\mathrm{pH} 7.2$, for $3 \mathrm{~h}$ at room temperature, washed three times, 10 min each, with PBS, and incubated for $1 \mathrm{~h}$ at $37^{\circ} \mathrm{C}$ with a cell-wall-digestion solution [2\% $(\mathrm{w} / \mathrm{v})$ cellulase (Sigma\#1794), $1 \%(\mathrm{w} / \mathrm{v})$ pectinase (Sigma\#17389), 0.05\% (w/v) macerozyme (Serva\#28302), 0.4\% (w/v) mannitol (Sigma\#M4125), 10\% glycerol (v/v) (Merck\#1.04094.1000) and $0.2 \%(\mathrm{v} / \mathrm{v})$ Triton X-100 (Sigma\#T9284)]. After cell wall digestion, the seedlings were washed with PBS, supplemented with $10 \%(\mathrm{v} / \mathrm{v})$ glycerol and $0.2 \%(\mathrm{v} / \mathrm{v})$ Triton X-100 three times, 10 min each. Excised root tips were placed on multi-well slides (EMS\#63422-06) coated with poly-L-lysine (Sigma\#P8920) and the samples were dehydrated with $100 \%$ methanol at $-20{ }^{\circ} \mathrm{C}$ for at least $30 \mathrm{~min}$.

Slides were washed twice, 5 min each, with PBS, supplemented with 1\% (v/v) NP40 (Sigma\#D67509) and $0.5 \%(\mathrm{w} / \mathrm{v})$, DOC (Sodium deoxycholate, Sigma\#I3021) and pre-treated with blocking buffer [2\% (w/v) BSA (Sigma\#A7030) and 0.05\% (v/v) Tween (Sigma\#P1379)] in PBS, for $30 \mathrm{~min}$, at room temperature. Then, they were incubated overnight at $37^{\circ} \mathrm{C}$ (in a humidified atmosphere) with mouse monoclonal antifibrillarin 38F3 antibody (Abcam\#ab4566), diluted 1:1000 in blocking buffer. Following incubation, wells were washed (3 times, 5 min each) with PBS, containing $1 \%(\mathrm{v} / \mathrm{v}), \mathrm{NP} 40$ and $0.5 \%(\mathrm{w} / \mathrm{v}), \mathrm{DOC}$ and incubated for $3 \mathrm{~h}$ at $37^{\circ} \mathrm{C}$ with a second antibody (anti-mouse IgG-Alexa 488, diluted 1:100). Then, samples were washed with the same buffer and nuclear DNA was stained with $4 \times 6$-diamidino-2phenylindole (DAPI 5X, Thermo\#62248). Finally, slides were washed with PBS and distilled water (twice, 5 min each) and mounted with DABCO (anti-fading agent, Sigma\#290734). The root tips were observed and photos were taken with a confocal laser microscope (Leica TCS SP5). Nucleolar size (area immunostained for fibrillarin) was measured using the quantitation software ImageJ.

\section{Cell membrane staining and cell proliferation quantification}


Seedlings were fixed in $5 \%(\mathrm{v} / \mathrm{v})$ paraformaldehyde for $3 \mathrm{~h}$ at room temperature, washed three times 10 min with PBS, pH 7.2 and incubated $1 \mathrm{~h}$ at $37^{\circ} \mathrm{C}$ with a cell-wall-digestion solution [ $1 \%(\mathrm{w} / \mathrm{v})$ pectinase (Sigma\#17389), 0.5\% (w/v) macerozyme (Serva\#28302), 0.4\% (w/v) mannitol (Sigma\#M4125), 10\% glycerol (v/v) (Merck\#1.04094.1000) and 0.2\% (v/v) Triton X-100 (Sigma\#T9284)]. After cell wall digestion, the seedlings were washed with PBS containing 10\% (v/v) glycerol and $0.2 \%(\mathrm{v} / \mathrm{v})$ Triton X-100 (3 times, 10 min each), excised root tips were placed on poly-L-lysine coated multi-well slides and the samples were dehydrated with $100 \%$ methanol at $-20^{\circ} \mathrm{C}$ for, at least, $30 \mathrm{~min}$.

Root tips were stained for $2 \mathrm{~h}$ at room temperature in darkness with dye solution [2\% ( $/ \mathrm{v})$ Renaissance (Renchem\#SCRI 2200) + 4\% (v/v) DMSO (Dimethyl sulfoxide, Sigma\#D8418) in PBS, pH 7.2]. Then, the samples were washed with PBS and distilled water (3 times, 5 min each) and DABCO (anti-fading agent) was added. Samples were observed in a confocal laser microscope (Leica TCS SP5) and images were taken. Finally, the rate of local cell production (number of cells $/ \mathrm{mm}$ ) [56] was measured in root meristematic cell layers using ImageJ software. DII-VENUS fluorescence intensities were extracted from the confocal images using the CellSeT segmentation tool, as described by Pound et al. [57].

\section{Histochemical GUS assay}

Seedlings were incubated in acetone at $-20^{\circ} \mathrm{C}$ for 3-4 days. Then, the samples were washed (twice, $10 \mathrm{~min}$ ) with $100 \mathrm{mM}$ sodium phosphate buffer and GUS signal was revealed by enzymatic reaction [5 mM potassium ferrocyanide and ferricyanide (Sigma\#P9387/Sigma\#P8131), $100 \mathrm{mM}$ sodium phosphate buffer and $40 \mathrm{mM} \mathrm{X-Glc} \mathrm{A} \mathrm{(Duchefa \# X1405.0100)]} \mathrm{overnight,} \mathrm{at} 37^{\circ} \mathrm{C}$, in darkness.

Reactions were stopped by several washings of samples in $50 \mathrm{mM}$ sodium phosphate buffer before being mounted with glycerol on $8 \times 8 \mathrm{~mm}$ well slides. The root tips were observed under a Leica DM2500 microscope and images were recorded with a Leica DFC320 CCD camera and processed with ImageJ software. Integrated optical density (I.O.D) was calculated (I.O.D = stained area $\times$ optical density (O.D) in the blue light spectrum) using an unstained zone of the root tip as blank.

\section{Sample processing for transcriptional analyses}

\section{RNA extraction}

Frozen samples were dissected by separating aerial parts (hypocotyls) from roots, and seeds (ungerminated or remnants) were discarded for avoiding any alterations of expression results. Total RNA from plant tissues (shoots and roots) was extracted with a commercial kit (RNA isolation from plant, NucleoSpin) following the manufacturer's instructions (MACHEREY-NAGEL, 740949.250). RNA quality was determined by Nanodrop2000 (Thermo) and they were stored at $-80^{\circ} \mathrm{C}$ until their further use.

\section{Pre-rRNA processing study in hypocotyls (RT-PCR)}

Extracted RNAs from aerial part were used to analyze ribosome biogenesis, specifically pre-rRNA processing, by conventional RT-PCR with probes corresponding to different External Transcribed Spacer (ETS) sequences of 45 S pre-rRNA (primary transcript) (Suppl. Table S1) [17, 58]. 
The samples $(5 \mu \mathrm{g})$ were treated with an extra DNase digestion (TURBO DNase Treatment and Removal Reagents, Ambion\#AM1907) for 60 min to eliminate contaminant DNA. First-strand cDNA synthesis was performed on $500 \mathrm{ng}$ of treated RNA with the Oligo(dT)15 (Promega\#C1101) and Random Primers (Promega\#C1181) using the SuperScript III Reverse Transcriptase kit following the manufacturer's instructions (Invitrogen\#18080-093). RNA quality was checked after DNase treatment and negative RT (RT-) control (without enzyme) was performed.

Amplification of the $5^{\prime}$ and $3^{\prime}$ ETS sequences from cDNA products (PCR products) was performed with enzyme GoTaq DNA Polymerase (Promega\#M7845) and oligonucleoltides 5'ETS (p1/p2), 5’ETS-P/18S (p3/p4), 5’ETS/18S (p5/p6), 25S/3'ETS (p7/p8) and 3'ETS (p9/p10) following the manufacturer's instructions. PCRs were performed in parallel in RT + and RT- samples. In addition, an extra negative control (no sample) with $\mathrm{H}_{2} \mathrm{Odd}$ and positive control (genomic DNA, $2.9 \mathrm{ng} / \mu \mathrm{l}$ ) were included.

PCR products $(5 \mu \mathrm{l})$ were loaded on an agarose gel [2\% $(\mathrm{w} / \mathrm{v})$ in $0.5 \times$ TAE (Tris Acetate-EDTA) buffer] and electrophoresis was developed for $1 \mathrm{~h}$ at 130V. Then, from each gel, images were recorded using Kodak Electrophoresis Documentation and Analysis System120 coupled to DC290 Zoom Digital Camera. Images were analyzed with Image J software and elF1 a transcription factor was used as loading control and internal standard (no expression changes in any experimental condition).

\section{Pre-rRNA processing and meristematic competence studies in roots (RT-qPCR)}

Quantitative RT-PCR (RT-qPCR) was performed in a single step with LightCycler 96 System (Roche) and Brilliant III Ultra-fast SYBR Green QRT-PCR Master Mix (Agilent Technologies\#600886) with primers corresponding to selected genes involved in ribosome biogenesis, cell cycle regulation, cell growth and auxin polar transport (Suppl. Table S2). RT-qPCR was performed in standardized conditions (40 cycles and $60^{\circ} \mathrm{C}$ hybridization phase temperature) after testing that all probe combinations produced a single peak (amplicon) and the RNA/probe concentration ratios were in the optimal efficiency range of the qPCR reaction. The Actin2 gene was used as an internal standard, and results were analyzed using the comparative cycle threshold method relative to input [59].

\section{Statistical analyses}

Statistical analyses of data were performed using SPSS 22.0 software (IBM). First, we checked the populations normal distribution (Shapiro-Wilk Test for $n<20$ or Kolmogorov-Smirnov Test for $n>20$ ) and their homoscedasticity (Levene Test).

Quantitative variables description was performed using mean and standard deviation values. Mean values were compared using the t-Student Test for independent samples (normal distribution and homoscedasticity) or by non-parametric U Mann-Whitney-Wilcoxon Test (non-normal distribution). Differences between samples were considered significant for a bilateral probability value, $p$, lower than 0.05 ( $p$-value $<0.05)$. 


\section{Abbreviations}

ETS

External Transcribed Spacer, either in the transcription unit of the rRNA genes, or in the pre-rRNA primary transcript.

$g$

Acceleration of gravity: $9.8 \mathrm{~m} \cdot \mathrm{s}^{-2}$

GUS

$\beta$-glucuronidase.

IOD

Integrated Optical Density.

RPM

Random Positioning Machine

RT-(q)PCR

Real Time-(quantitative) Polymerase Chain Reaction

YFP

Yellow Fluorescent Protein.

\section{Declarations}

\section{Ethics approval and consent to participate}

Not applicable

\section{Consent for publication}

Not applicable

\section{Availability of data and materials}

The datasets used and/or analyzed during the current study are available from the corresponding author on reasonable request.

\section{Competing interests}

The authors declare that they have no competing interests.

\section{Funding}


Work performed in the authors' laboratory was financially supported by the Agencia Estatal de Investigación of the Spanish Ministry of Science an Innovation, Grants \#ESP2015-64323-R and \#RTI2018-099309-B-I00 (co-funded by EU-ERDF) These grants covered all the expenses necessary to perform the experiments, except the salaries of personnel. The use of the facilities of microgravity simulation was provided by the ESA-CORA-Ground Based Facilities Program, contract Ref. \#4000105761. This contract covered the fee for the use of the facility and the travel expenses of AM to Toulouse.

\section{Authors' contributions}

FJM designed the objectives of the work and, with a major contribution of $\mathrm{RH}$, designed the experimental sequence and procedures, supervised the entire work and were the major contributors to the final version of the manuscript. AM performed all the experimental work, including statistics and bioinformatics, and wrote the first draft of the manuscript. VPL managed the facility for microgravity simulation and assisted in the incubation of samples in this facility. JSV designed the experiments involving pre-rRNA processing, supervised them, and provided the oligos used in these experiments. ADB assisted in the experiments of pre-rRNA processing. All authors read and approved the final manuscript.

\section{Acknowledgements}

AM was recipient of a contract of the Program for Young Researchers Training of the Agencia Estatal de Investigación of the Spanish Ministry of Science an Innovation Ref. \#BES-2013-063933. We acknowledge support of the publication fee by the CSIC Open Access Publication Support Initiative through its Unit of Information Resources for Research (URICI).

\section{References}

1. Molas ML, Kiss JZ. Phototropism and gravitropism in plants. Adv Bot Res. 2009;49:1-34 doi.

2. Vandenbrink JP, Kiss JZ, Herranz R, Medina FJ. Light and gravity signals synergize in modulating plant development. Front Plant Sci. 2014;5:563 doi. doi:10.3389/fpls.2014.00563.

3. Christie JM, Murphy AS. Shoot phototropism in higher plants: New light through old concepts. Am J Bot. 2013;100(1):35-46. doi:10.3732/ajb.1200340.

4. Ottenschlager I, Wolff P, Wolverton C, Bhalerao RP, Sandberg G, Ishikawa H, Evans M, Palme K. Gravity-regulated differential auxin transport from columella to lateral root cap cells. Proc Natl Acad Sci USA. 2003;100(5):2987-91 doi.

5. Perrot-Rechenmann C. Cellular responses to auxin: division versus expansion. Cold Spring Harb Perspect Biol. 2010;2(5):a001446 doi. doi:10.1101/cshperspect.a001446.

6. Scheres B, Benfey P, Dolan L: Root Development. In: The Arabidopsis Book. Edited by Somerville CR, Meyerowitz EM. Rockville, MD: American Society of Plant Biologists; 2002: 1-18 doi. 
7. Mizukami Y. A matter of size: developmental control of organ size in plants. Curr Opinion Plant Biol. 2001;4(6):533-9 doi. doi:10.1016/S1369-5266(00)00212-0.

8. Baserga R. Is cell size important? Cell Cycle. 2007;6(7):814-6 doi.

9. Sablowski R, Carnier Dornelas M. Interplay between cell growth and cell cycle in plants. J Exp Bot. 2014;65(10):2703-14. doi:10.1093/jxb/ert354.

10. Weis BL, Kovacevic J, Missbach S, Schleiff E. Plant-Specific Features of Ribosome Biogenesis. Trends Plant Sci. 2015;20(11):729-40. doi:http://dx.doi.org/10.1016/j.tplants.2015.07.003.

11. Medina FJ, Cerdido A, De Cárcer G. The functional organization of the nucleolus in proliferating plant cells. Eur J Histochem. 2000;44(2):117-31 doi.

12. $10.1016 /$ S0065-2296(08)00001-3

Sáez-Vásquez J, Medina FJ: The Plant Nucleolus. In: Advances in Botanical Research vol 47. Edited by Kader JC, Delseny M. San Diego, CA: Elsevier; 2008: 1-46 doi: doi: 10.1016/S00652296(08)00001-3.

13. 10.1016/j.gene.2014.09.023

Durut N, Sáez-Vásquez J: Nucleolin: Dual roles in rDNA chromatin transcription. Gene 2014, In press(0) doi: 10.1016/j.gene.2014.09.023.

14. Medina FJ, Gonzalez-Camacho F, Manzano Al, Manrique A, Herranz R. Nucleolin, a major conserved multifunctional nucleolar phosphoprotein of proliferating cells. J Appl Biomed. 2010;8(3):141-50. doi:10.2478/v10136-009-0017-5.

15. Mongelard F, Bouvet P. Nucleolin: a multiFACeTed protein. Trends Cell Biol. 2007;17(2):80-6 doi.

16. Pontvianne F, Matia I, Douet J, Tourmente S, Medina FJ, Echeverria M, Saez-Vasquez J.

\section{Characterization of AtNUC-L1 reveals a central role of nucleolin in nucleolus organization and} silencing of AtNUC-L2 gene in Arabidopsis. Mol Biol Cell. 2007;18(2):369-79. doi:10.1091/mbc.E0608-0751.

17. Durut N, Abou-Ellail M, Pontvianne F, Das S, Kojima H, Ukai S, de Bures A, Comella P, Nidelet S, Rialle S, et al. A Duplicated NUCLEOLIN Gene with Antagonistic Activity Is Required for Chromatin Organization of Silent 45S rDNA in Arabidopsis. Plant Cell. 2014;26(3):1330-44. doi:10.1105/tpc.114.123893.

18. Durut N, Abou-Ellail M, Comella P, Jobet E, de Bures A, Sáez-Vásquez J. NUCLEOLIN: Similar and Antagonistic Roles in Arabidopsis thaliana. In: 26th European Low Gravity Research Association Biennial Symposium and General Assembly: 2019; Granada (Spain).

19. López-Juez E, Dillon E, Magyar Z, Khan S, Hazeldine S, de Jager SM, Murray JAH, Beemster GTS, Bögre L, Shanahan H. Distinct light-Initiated gene expression and cell cycle programs in the shoot apex and cotyledons of Arabidopsis. Plant Cell. 2008;20(4):947-68. doi:10.1105/tpc.107.057075.

20. Mohammed B, Bilooei SF, Dóczi R, Grove E, Railo S, Palme K, Ditengou FA, Bögre L, López-Juez E. Converging Light, Energy and Hormonal Signaling Control Meristem Activity, Leaf Initiation, and Growth. Plant Physiol. 2018;176(2):1365-81. doi:10.1104/pp.17.01730. 
21. Silva-Navas J, Moreno-Risueño MA, Manzano C, Téllez-Robledo B, Navarro-Neila S, Carrasco V, Pollmann S, Gallego FJ, del Pozo JC. Flavonols Mediate Root Phototropism and Growth through Regulation of Proliferation-to-Differentiation Transition. Plant Cell. 2016;28(6):1372-87. doi:10.1105/tpc.15.00857.

22. Caldana C, Li Y, Leisse A, Zhang Y, Bartholomaeus L, Fernie AR, Willmitzer L, Giavalisco P. Systemic analysis of inducible target of rapamycin mutants reveal a general metabolic switch controlling growth in Arabidopsis thaliana. Plant J. 2013;73(6):897-909. doi:10.1111/tpj.12080.

23. Xiong Y, McCormack M, Li L, Hall Q, Xiang C, Sheen J. Glucose-TOR signalling reprograms the transcriptome and activates meristems. Nature. 2013;496(7444):181-6 doi.

24. Manzano A, Herranz R, den Toom LA, te Slaa S, Borst G, Visser M, Medina FJ, van Loon JJWA. Novel, Moon and Mars, partial gravity simulation paradigms and their effects on the balance between cell growth and cell proliferation during early plant development. npj Microgravity. 2018;4(1):9 doi. doi:10.1038/s41526-018-0041-4.

25. Matía I, González-Camacho F, Herranz R, Kiss JZ, Gasset G, van Loon JJWA, Marco R, Medina FJ. Plant cell proliferation and growth are altered by microgravity conditions in spaceflight. J Plant Physiol. 2010;167(3):184-93. doi:10.1016/j.jplph.2009.08.012.

26. Manzano Al, Larkin O, Dijkstra C, Anthony P, Davey M, Eaves L, Hill R, Herranz R, Medina FJ. Meristematic cell proliferation and ribosome biogenesis are decoupled in diamagnetically levitated Arabidopsis seedlings. BMC Plant Biol. 2013;13(1):124 doi. doi:10.1186/1471-2229-13-124.

27. Herranz R, Anken R, Boonstra J, Braun M, Christianen PCM, de Geest M, Hauslage J, Hilbig R, Hill RJA, Lebert $M$, et al. Ground-based facilities for simulation of microgravity: organism-specific recommendations for their use, and recommended terminology. Astrobiology. 2013;13(1):1-17. doi:10.1089/ast.2012.0876.

28. Comella P, Pontvianne F, Lahmy S, Vignols F, Barbezier N, DeBures A, Jobet E, Brugidou E, Echeverria $M$, Saez-Vasquez J. Characterization of a ribonuclease III-like protein required for cleavage of the prerRNA in the 3'ETS in Arabidopsis. Nucl Acids Res. 2008;36(4):1163-75. doi:10.1093/nar/gkm1130.

29. Sáez-Vásquez J, Caparros-Ruiz D, Barneche F, Echeverría M. A plant snoRNP complex containing snoRNAs, fibrillarin, and nucleolin-like proteins is competent for both rRNA gene binding and prerRNA processing in vitro. Mol Cell Biol. 2004;24(16):7284-97 doi.

30. Musielak TJ, Schenkel L, Kolb M, Henschen A, Bayer M. A simple and versatile cell wall staining protocol to study plant reproduction. Plant Reproduction. 2015;28(3):161-9. doi:10.1007/s00497015-0267-1.

31. Colon-Carmona A, You R, Haimovitch-Gal T, Doerner P. Spatio-temporal analysis of mitotic activity with a labile cyclin-GUS fusion protein. Plant J. 1999;20(4):503-8 doi.

32. Bernstein KA, Bleichert F, Bean JM, Cross FR, Baserga SJ. Ribosome biogenesis is sensed at the start cell cycle checkpoint. Mol Biol Cell. 2007;18(3):953-64. doi:10.1091/mbc.E06-06-0512.

33. Brunoud G, Wells DM, Oliva M, Larrieu A, Mirabet V, Burrow AH, Beeckman T, Kepinski S, Traas J, Bennett MJ, et al. A novel sensor to map auxin response and distribution at high spatio-temporal 
resolution. Nature. 2012;482(7383):103-6 doi.

http://www.nature.com/nature/journal/v482/n7383/abs/nature10791.html\#supplementaryinformation.

34. Ferl RJ, Paul A-L. The effect of spaceflight on the gravity-sensing auxin gradient of roots: GFP reporter gene microscopy on orbit. npj Microgravity. 2016;2:15023 doi. doi:10.1038/npjmgrav.2015.23.

35. $10.1371 /$ journal.pone.0180186

Paul A-L, Sng NJ, Zupanska AK, Krishnamurthy A, Schultz ER, Ferl RJ: Genetic dissection of the Arabidopsis spaceflight transcriptome: Are some responses dispensable for the physiological adaptation of plants to spaceflight? PLOS ONE 2017, 12(6):e0180186 doi: doi:

10.1371/journal.pone.0180186.

36. Hoson T, Soga K, Wakabayashi K, Kamisaka S, Tanimoto E. Growth and cell wall changes in rice roots during spaceflight. Plant Soil. 2003;255(1):19-26 doi.

37. Driss-Ecole D, Legué V, Carnero-Diaz E, Perbal G. Gravisensitivity and automorphogenesis of lentil seedling roots grown on board the International Space Station. Physiol Plant. 2008;134(1):191-201. doi:10.1111/j.1399-3054.2008.01121.x.

38. Millar KD, Johnson CM, Edelmann RE, Kiss JZ. An endogenous growth pattern of roots is revealed in seedlings grown in microgravity. Astrobiology. 2011;11:787-97 doi.

39. Schultz ER, Paul A-L, Ferl RJ. Root Growth Patterns and Morphometric Change Based on the Growth Media. Microgravity Science Technology. 2016;28(6):621-31. doi:10.1007/s12217-016-9514-9.

40. Roy R, Bassham DC. Root growth movements: Waving and skewing. Plant Sci. 2014;221-222:42-7. doi:10.1016/j.plantsci.2014.01.007.

41. Paul A-L, Amalfitano C, Ferl R. Plant growth strategies are remodeled by spaceflight. BMC Plant Biol. 2012;12(1):232 doi. doi:10.1186/1471-2229-12-232.

42. Nakashima J, Liao F, Sparks JA, Tang Y, Blancaflor EB. The actin cytoskeleton is a suppressor of the endogenous skewing behaviour of Arabidopsis primary roots in microgravity. Plant Biol. 2014;16(s1):142-50. doi:10.1111/plb.12062.

43. Califar B, Sng NJ, Zupanska A, Paul A-L, Ferl RJ. Root Skewing-Associated Genes Impact the Spaceflight Response of Arabidopsis thaliana. Front Plant Sci 2020, 11(239) doi:10.3389/fpls.2020.00239.

44. Kamal KY, Herranz R, van Loon JJWA, Medina FJ. Simulated microgravity, Mars gravity, and $2 \mathrm{~g}$ hypergravity affect cell cycle regulation, ribosome biogenesis, and epigenetics in Arabidopsis cell cultures. Sci Rep. 2018;8(1):6424 doi. doi:10.1038/s41598-018-24942-7.

45. Manzano Al, Herranz R, Manzano A, Van Loon JJWA, Medina FJ. Early effects of altered gravity environments on plant cell growth and cell proliferation: Characterization of morphofunctional nucleolar types in an Arabidopsis cell culture system. Frontiers in Astronomy Space Sciences 2016, 3 doi:10.3389/fspas.2016.00002. 
46. Boucheron-Dubuisson E, Manzano Al, Le Disquet I, Matía I, Sáez-Vasquez J, van Loon JJWA, Herranz R, Carnero-Diaz E, Medina FJ. Functional alterations of root meristematic cells of Arabidopsis thaliana induced by a simulated microgravity environment. J Plant Physiol. 2016;207:30-41 doi. doi:10.1016/j.jplph.2016.09.011.

47. Janda T, Hideg É, Vanková R. The Role of Light in Abiotic Stress Acclimation. Front Plant Sci 2020, 11(184) doi:10.3389/fpls.2020.00184.

48. Blilou I, Xu J, Wildwater M, Willemsen V, Paponov IA, Friml J, Heidstra R, Aida M, Palme K, Scheres B. The PIN efflux facilitator network controls growth and patterning in Arabidopsis roots. Nature. 2005;433(7021):39-44 doi.

49. Swarup R, Friml J, Marchant A, Ljung K, Sandberg G, Palme K, Bennett M. Localization of the auxin permease AUX1 suggests two functionally distinct hormone transport pathways operate in the Arabidopsis root apex. Genes Dev. 2001;15(20):2648-53. doi:10.1101/gad.210501.

50. Ueda J, Miyamoto K, Uheda E, Oka M, Yano S, Higashibata A, Ishioka N. Close relationships between polar auxin transport and graviresponse in plants. Plant Biol. 2014;16(s1):43-9. doi:10.1111/plb.12101.

51. Link BM, Busse JS, Stankovic B. Seed-to-Seed-to-Seed growth and development of Arabidopsis in microgravity. Astrobiology. 2014;14(10):866-75 doi. doi:10.1089/ast.2014.1184.

52. Massa GD, Newsham G, Hummerick ME, Caro JL, Stutte GW, Morrow RC, Wheeler RM. Preliminary species and media selection for the Veggie space hardware. Gravitational and Space Research 2013, 1 (1) doi.

53. De Micco V, De Pascale S, Paradiso R, Aronne G. Microgravity effects on different stages of higher plant life cycle and completion of the seed-to-seed cycle. Plant Biol. 2014;16:31-8. doi:10.1111/plb.12098.

54. Valbuena MA, Manzano A, Vandenbrink JP, Pereda-Loth V, Carnero-Diaz E, Edelmann RE, Kiss JZ, Herranz R, Medina FJ. The combined effects of real or simulated microgravity and red-light photoactivation on plant root meristematic cells. Planta. 2018;248(3):691-704 doi. doi:10.1007/s00425-018-2930-x.

55. Ferreira P, Hemerly AS, De Almeida Engler J, Bergounioux C, Burssens S, Van Montagu M, Engler G, Inzé D. Three discrete classes of Arabidopsis cyclins are expressed during different intervals of the cell cycle. Proc Natl Acad Sci USA. 1994;91:11313-7 doi.

56. Beemster GTS, Baskin TI. Analysis of cell division and elongation underlying the developmental acceleration of root growth in Arabidopsis thaliana. Plant Physiol. 1998;116(4):1515-26. doi:10.1104/pp.116.4.1515.

57. Pound MP, French AP, Wells DM, Bennett MJ, Pridmore TP. CellSeT: Novel Software to Extract and Analyze Structured Networks of Plant Cells from Confocal Images. Plant Cell. 2012;24(4):1353-61. doi:10.1105/tpc.112.096289.

58. Pontvianne F, Abou-Ellail M, Douet J, Comella P, Matia I, Chandrasekhara C, DeBures A, Blevins T, Cooke R, Medina FJ, et al. Nucleolin is required for DNA methylation state and the expression of rRNA 
gene variants in Arabidopsis thaliana. PLoS Genet. 2010;6(11):e1001225 doi.

doi:10.1371/journal.pgen.1001225.

59. Livak KJ, Schmittgen TD. Analysis of Relative Gene Expression Data Using Real-Time Quantitative PCR and the $2-\Delta \Delta$ CT Method. Methods. 2001;25(4):402-8.

doi:https://doi.org/10.1006/meth.2001.1262.

Figures 


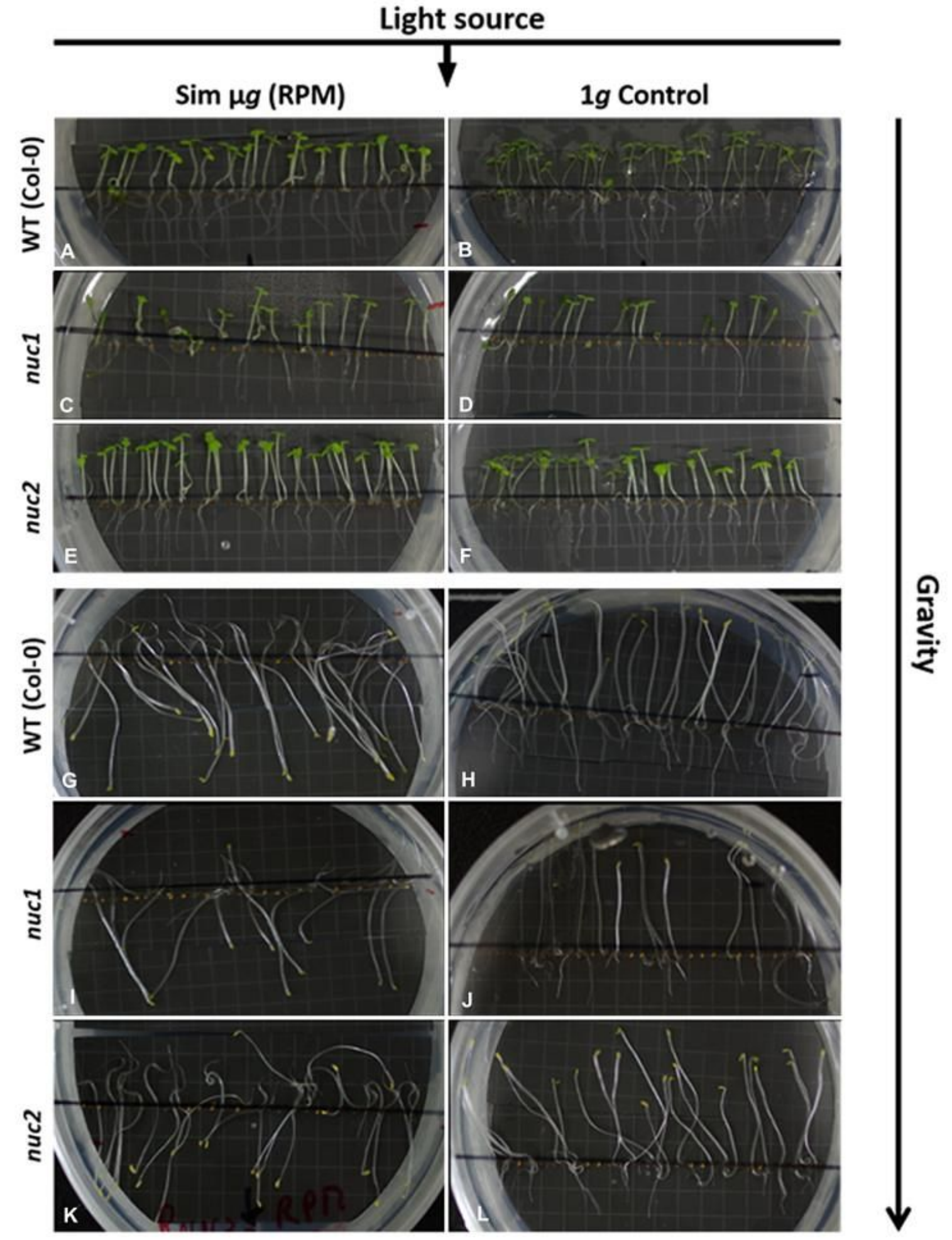

Figure 1

Arabidopsis thaliana seedlings grown under simulated microgravity (RPM) and $1 \mathrm{~g}$ control conditions. Images of 6-day-old seedlings (Col-0, nuc1 and nuc2) grown under simulated microgravity (left) either with photoperiod regime (A-F) or darkness (G-L) and their corresponding $1 \mathrm{~g}$ control (right). Gravity vector and light source direction were indicated in the figure. 


\section{Photoperiod}

A

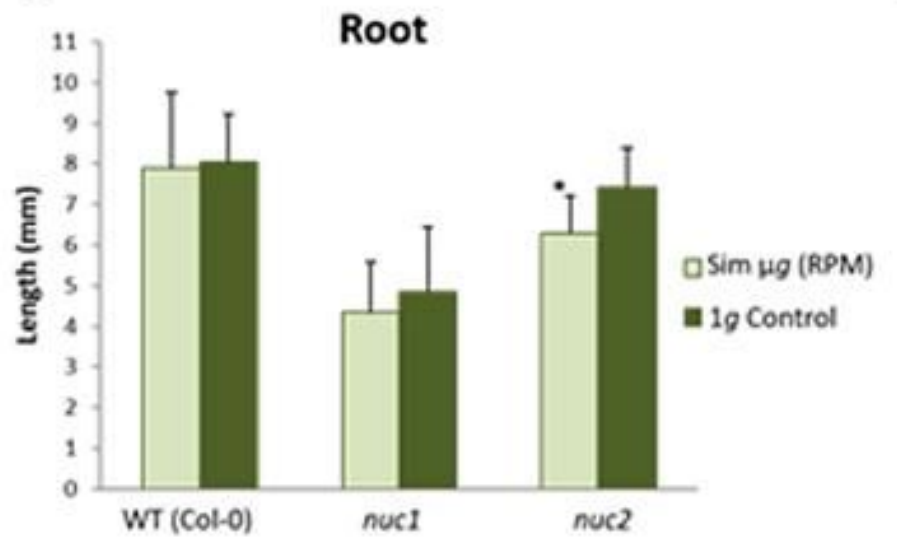

B

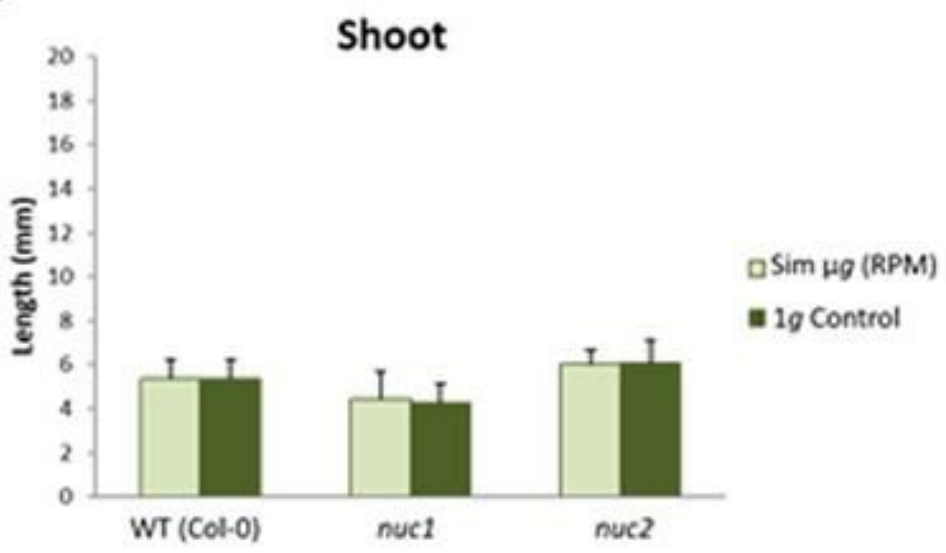

Darkness

C

Root

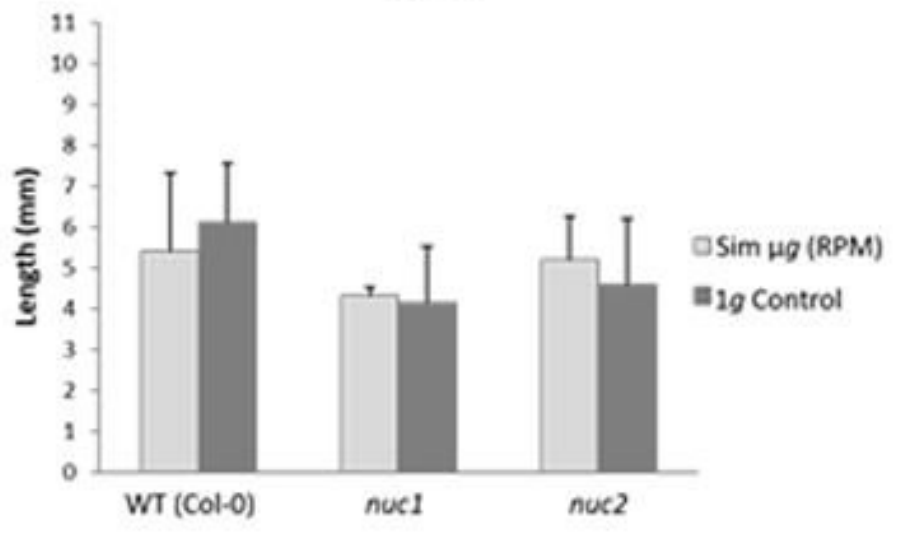

D

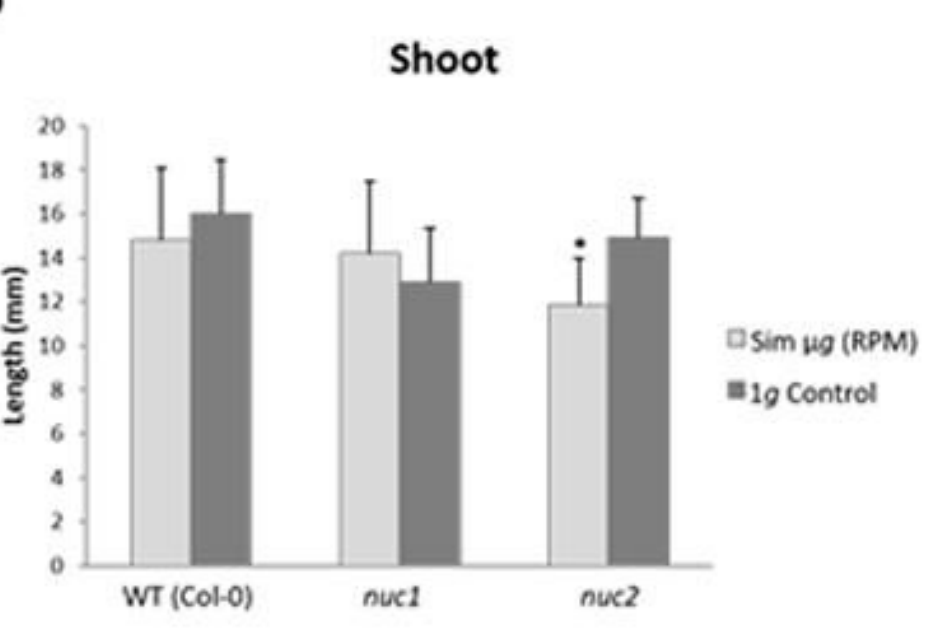

Figure 2

Length of root $(B, D)$ and shoot $(A, C)$ in seedlings grown at simulated microgravity under a photoperiod regime $(A, B)$ or in darkness $(C, D)$. Bars indicate standard deviation. Asterisks $\left({ }^{*}\right)$ indicate a significant difference ( $p$-value<0.05, T-Student Test) between samples of the same genotype in different gravity conditions. 
A

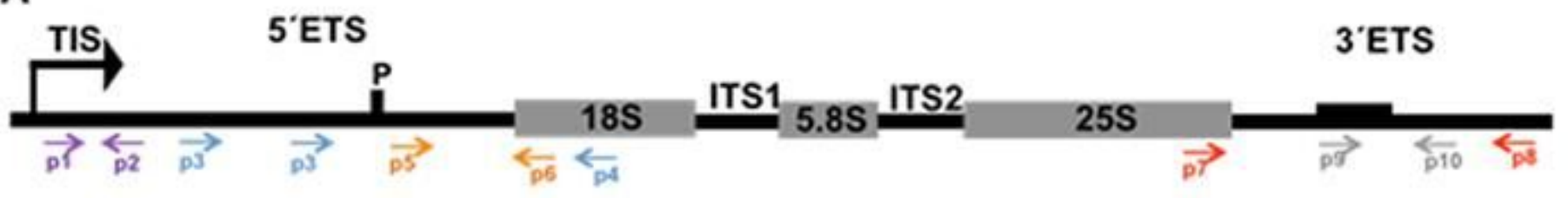

B Photoperiod

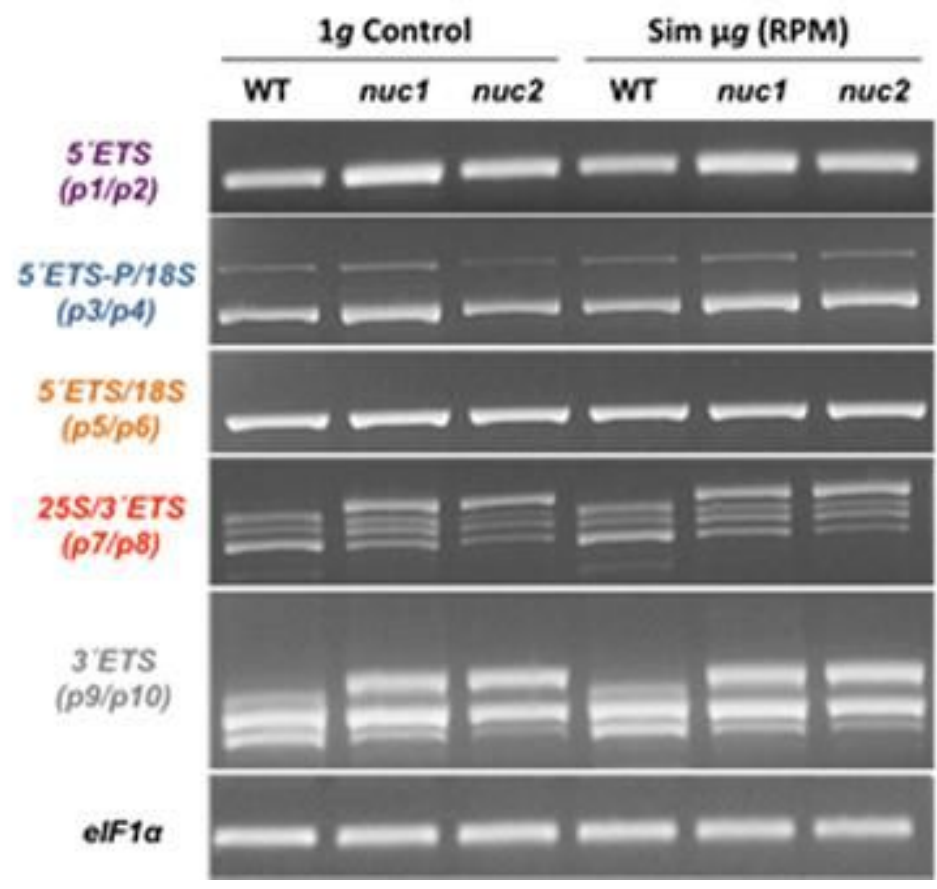

\section{Darkness}

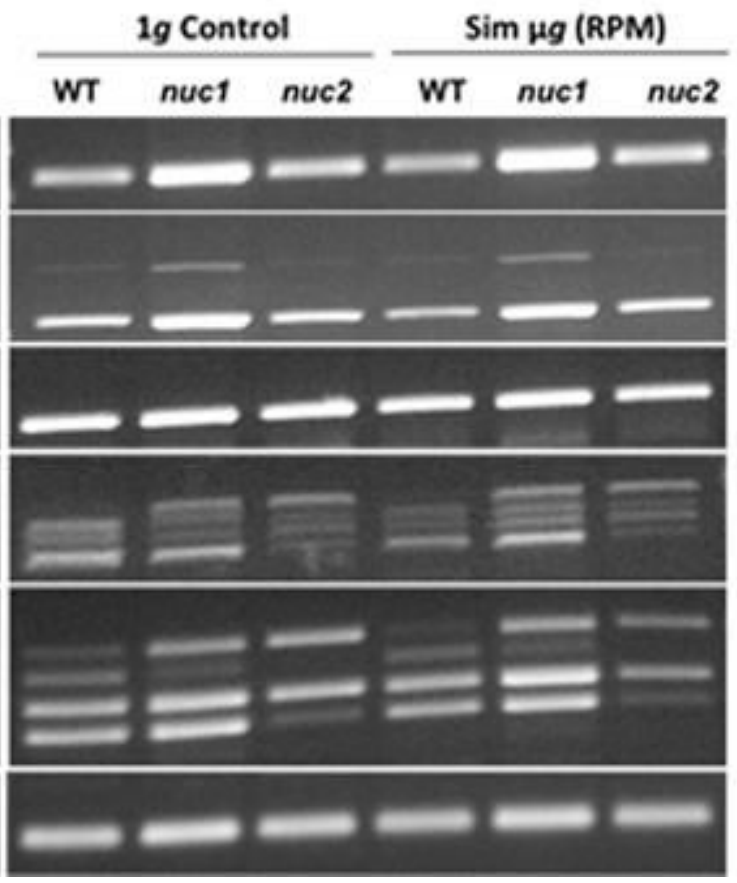

\section{Figure 3}

Ribosome biogenesis study in aerial part (hypocotyl) of Arabidopsis thaliana seedlings (Col-0, nuc1 and nuc2) grown under simulated microgravity and ground gravity level by RT-PCR. A) Scheme of $45 \mathrm{~S}$ prerRNA indicating amplification sequences for each primers pair, 5'ETS (p1/p2), 5'ETS-P/18S (p3/p4); $5^{\prime} E T S / 18 S$ (p5/p6), 25S/3'ETS (p7/p8) and 3'ETS (p9/p10). Agarose gel images of seedlings grown with photoperiod regime (B) or in darkness (C). The images shown in (B) and (C) were cropped from the originals shown in Figs. S6 and S7, respectively. 
A

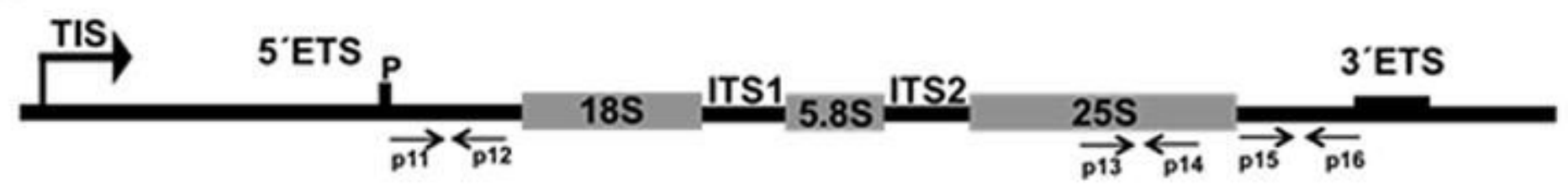

Photoperiod

B

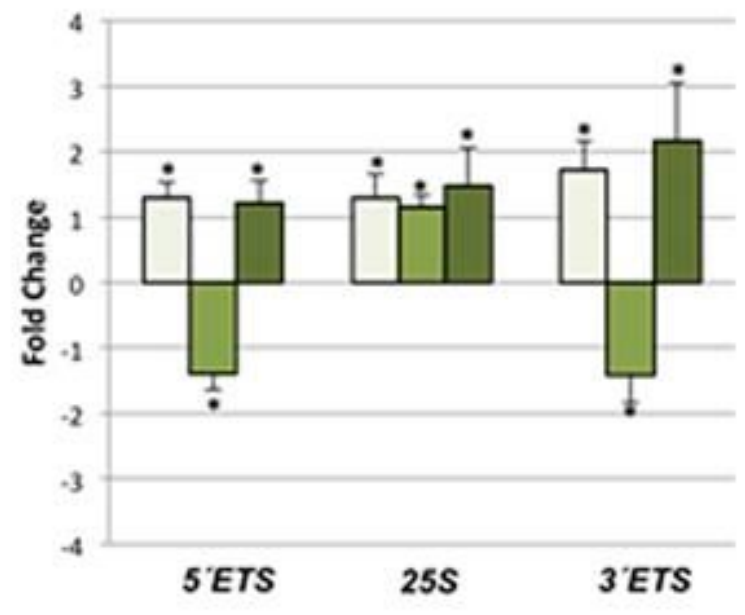

Darkness

C

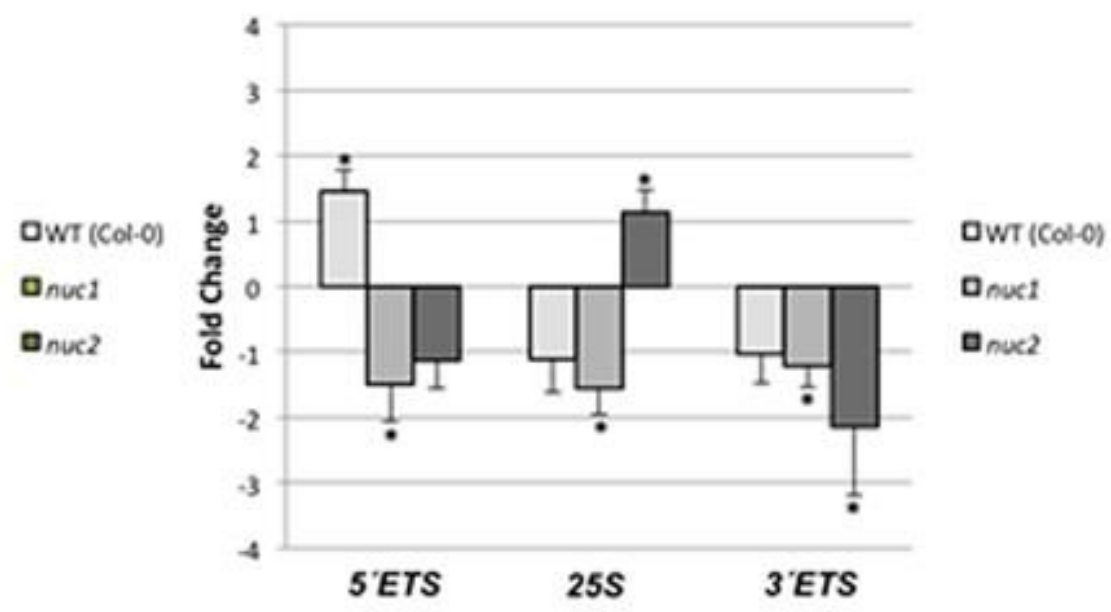

Figure 4

Analysis of primary transcript (45S pre-rRNA) in roots of 6-day-old Arabidopsis thaliana seedlings (Col-0, nuc1 and nuc2) by RT-qPCR. A) Scheme of 45 S pre-rRNA indicating amplification sequences for each primers pair, 5'ETS (p11/p12), 25S (p13/p14) and 3'ETS (p15/p16). Relative amplification (Fold Change) under simulated microgravity (RPM) respect to $1 \mathrm{~g}$ control of 5'ETS and 3'ETS ends and 25S RNA. B) Seedlings grown with photoperiod regime. C) Seedlings grown in absence of light (darkness). Bars indicate standard deviation. * Significant differences respect to $1 \mathrm{~g}$ control ( $\mathrm{p}$-value $<0.05$, T-Student Test) (three biological replicates). 


\section{A \\ Photoperiod}

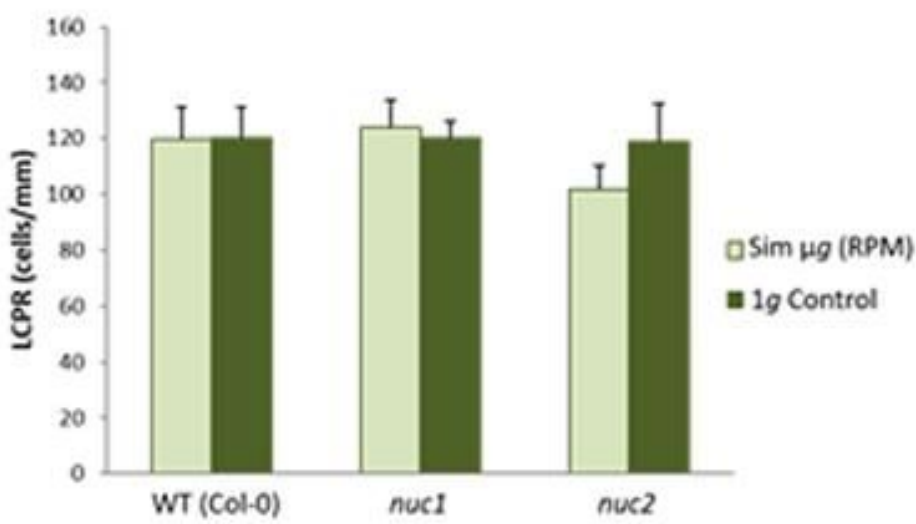

B

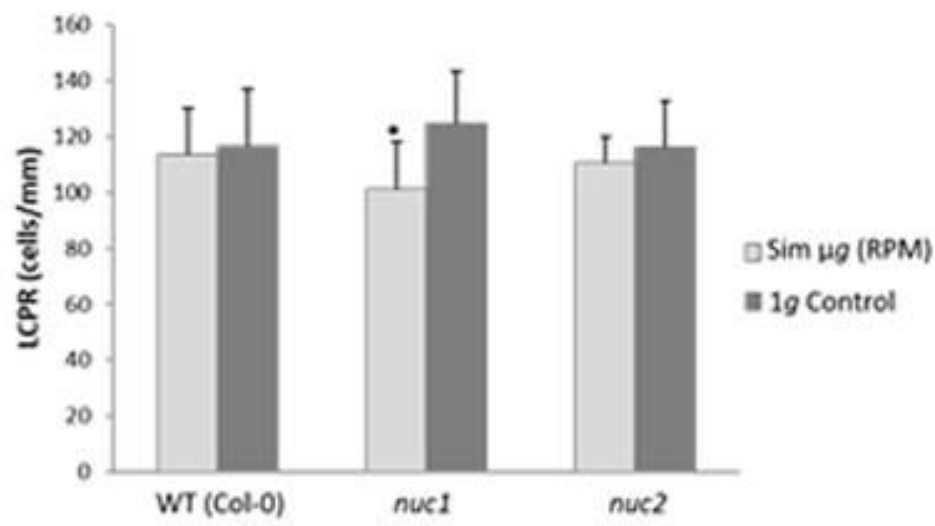

C
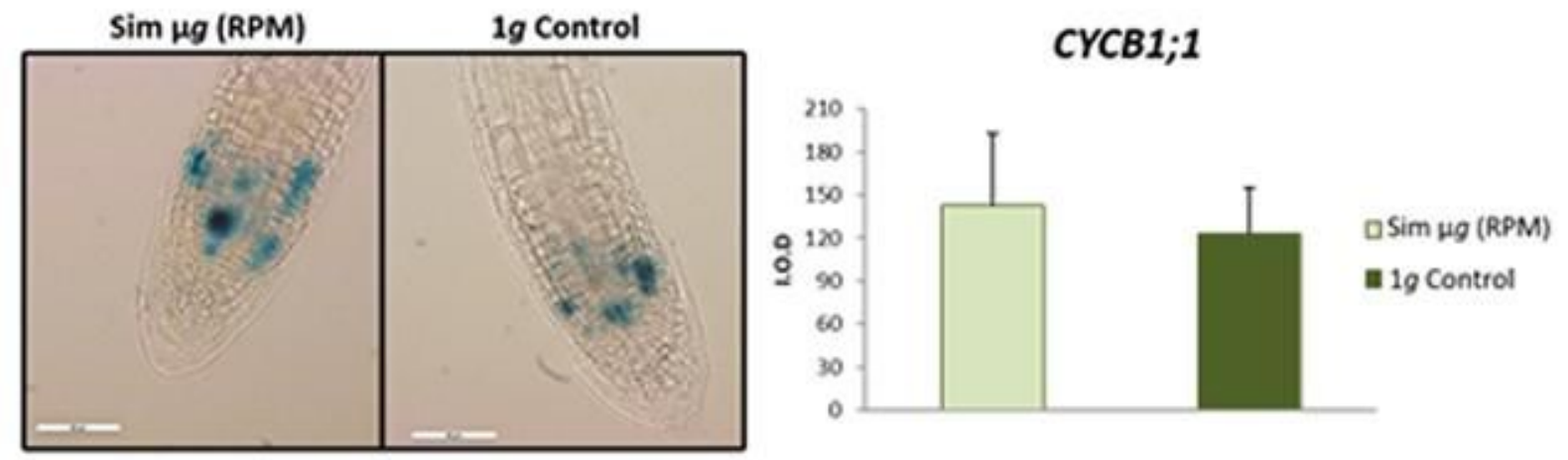

Figure 5

Cell proliferation rate in root meristematic cells of seedlings grown under simulated microgravity (RPM) and $1 \mathrm{~g}$ control conditions with photoperiod regime (A) and in darkness (B). Cyclin B1 expression in the root meristem determined by the GUS signal in a reporter line. An example of a root tip is provided for simulated microgravity and $1 \mathrm{~g}$ control conditions under photoperiod regime (C). In the graph, the Cyclin B1 signal has been quantified as the optical density (I.O.D). Bars indicate standard deviation. Asterisks (*) indicate a significant difference ( $p$-value $<0.05$, T-Student Test) between samples of the same genotype in different gravity conditions.

Photoperiod

A

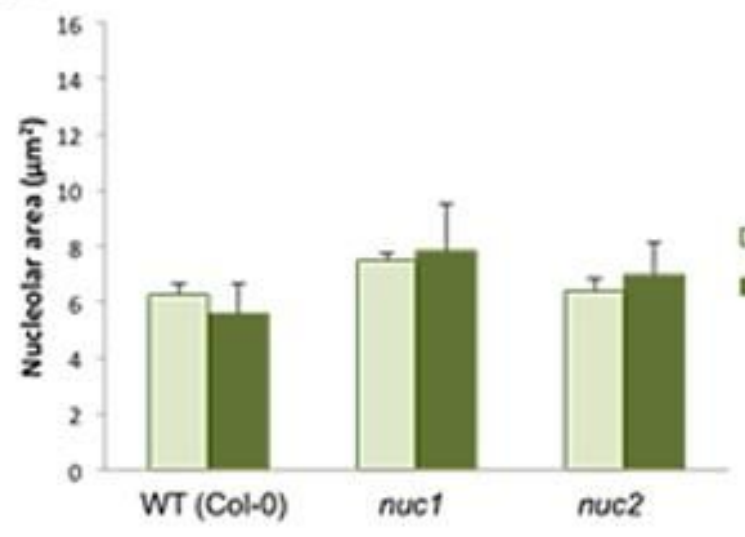

\section{Darkness}

\section{B}

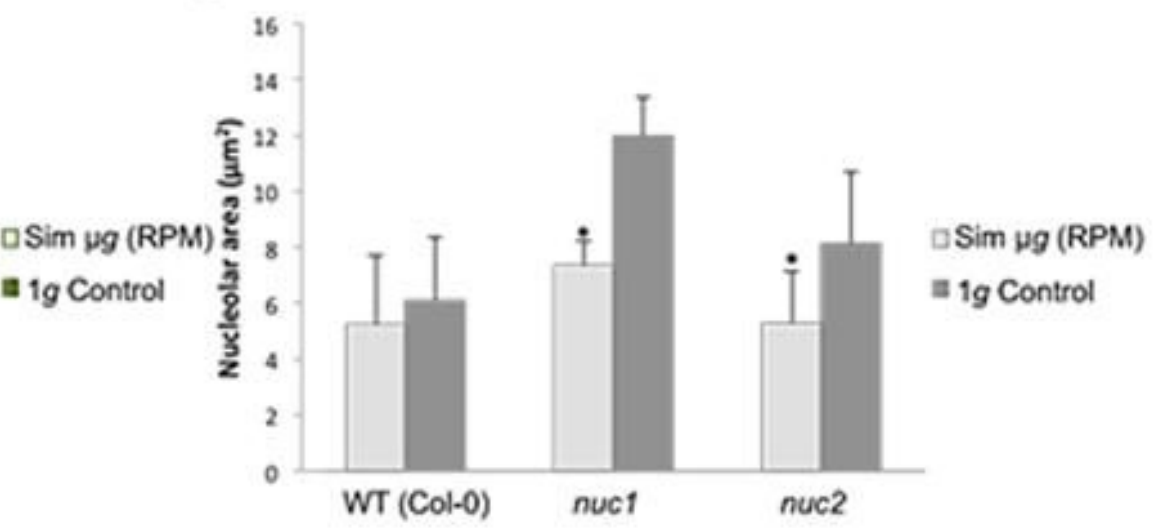


Figure 6

Cell growth rate (average size of the nucleolus determined by the immunohistological detection of fibrillarin) under simulated microgravity and $1 \mathrm{~g}$ control for seedlings grown for 6 days with photoperiod (A) or in darkness conditions (B). Bars indicative standard deviation. Asterisks ${ }^{*}$ ) indicate a significant difference ( $p$-value $<0.05$, T-Student Test) between samples of the same genotype in different gravity conditions.

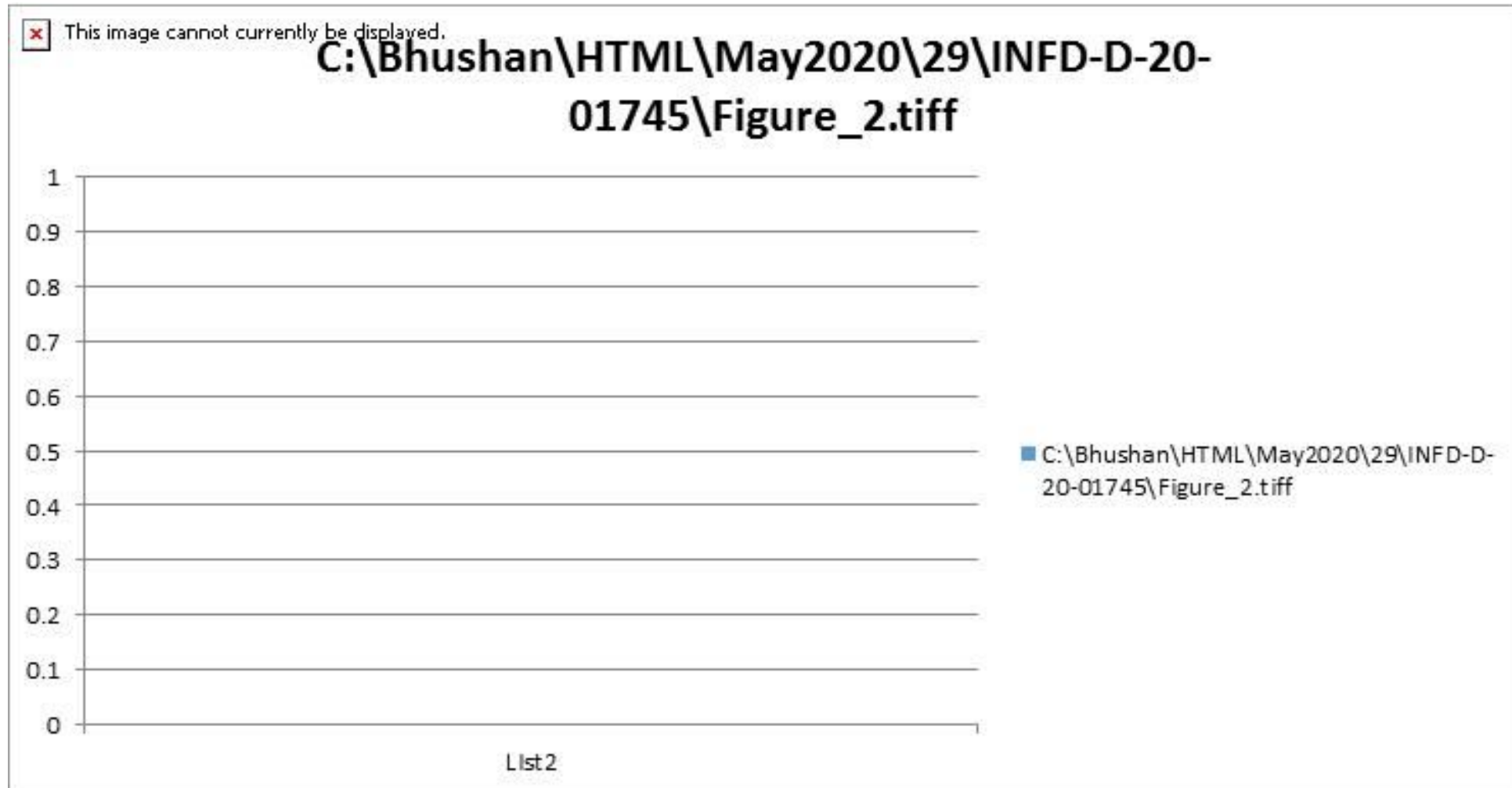

\section{Figure 7}

Auxin distribution pattern in root tips of DII-VENUS seedlings grown for 6 days under simulated microgravity (RPM) and $1 \mathrm{~g}$ control condition with photoperiod regime (top), or in darkness condition (down). The yellow fluorescence signal corresponds to the expression of YFP VENUS protein and blue fluorescence signal corresponds to the cell membrane staining with Renaissance dye. In each experimental condition, a central section with the corresponding fluorescence signal intensity (left) and maximum projection of yellow fluorescence signal (right) are shown. 


\section{Photoperiod}

A

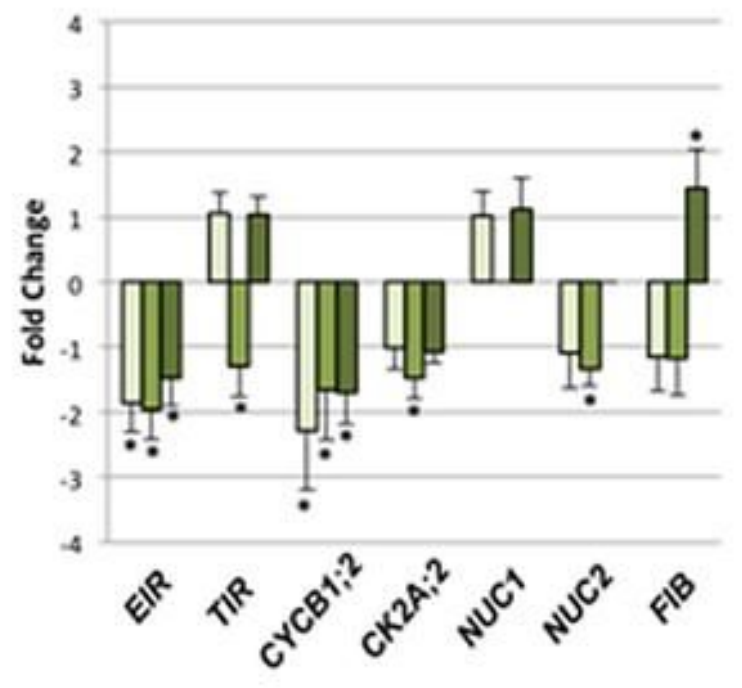

Darkness

B

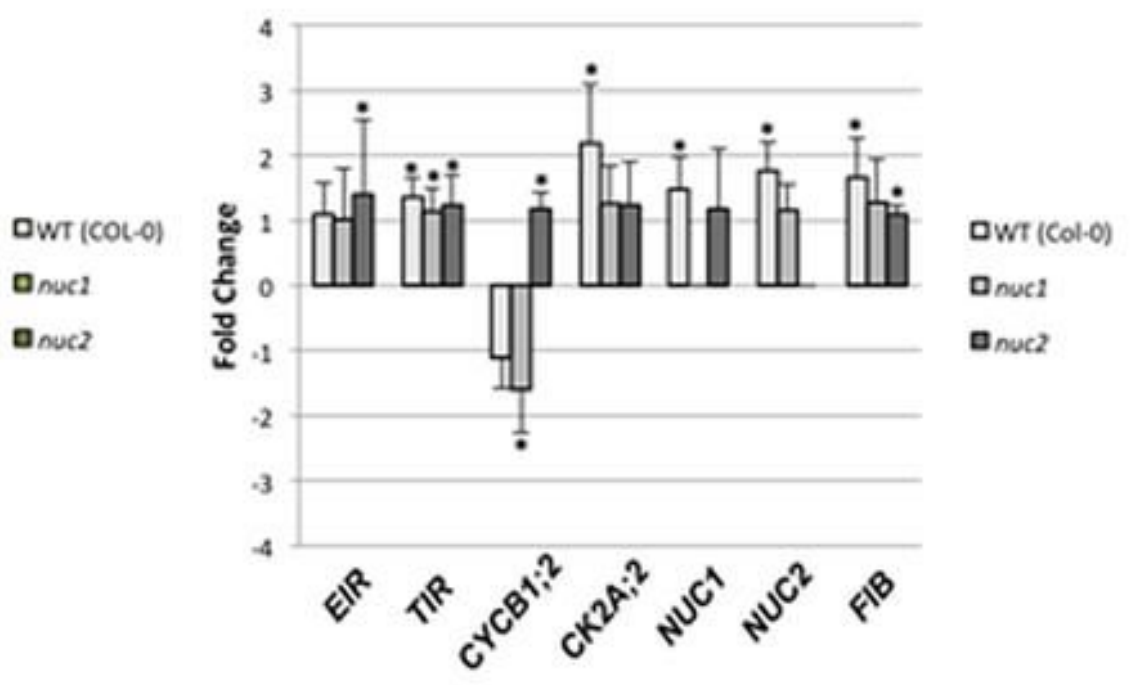

Figure 8

Relative expression of marker genes of auxin transport/perception, cell proliferation and cell growth in Arabidopsis thaliana seedlings (Col-0, nuc1 and nuc2) grown under simulated microgravity with photoperiod regime (A), or darkness (B), for 6 days. Histograms indicate the average difference in expression (Fold Change) between the microgravity samples versus $1 \mathrm{~g}$ control samples, calculated in three biological replicates. * Significant differences respect to $1 \mathrm{~g}$ control ( $\mathrm{p}$-value $<0.05$, T-Student Test) (Photoperiod: EIR, TIR, CYCB1;2 and FIB. Darkness: EIR, TIR, NUC1, FIB). * Significant differences respect to $1 \mathrm{~g}$ control ( $p$-value $<0.05$, U Mann-Whitney-Wilcoxon Test) (Photoperiod: CK2A;2 and NUC2. Darkness: CYCB1;2, CK2A;2 and NUC2).

\section{Supplementary Files}

This is a list of supplementary files associated with this preprint. Click to download.

- SupplementalMaterialPhotoperiodv5.docx 